\title{
A FORMAÇÃO DO ENGENHEIRO DO FUTURO: AS CONTRIBUIÇÕES DO MOVIMENTO EMPRESA JÚNIOR
}

\author{
Thalys Gean Maciel Martins - tgean@id.uff.br \\ Nathália Pires Monteiro - nathaliapires@id.uff.br \\ Geraldo de Souza Ferreira - geraldoferreira@id.uff.br
}

Universidade Federal Fluminense, Escola de Engenharia, TEQ - Departamento de Engenharia Química e de Petróleo, Rua Passos da Pátria, 156 - Bloco D - Sala 264, 21.210-240 - Niterói RJ.

\begin{abstract}
Resumo: O Movimento Empresa Júnior (MEJ), desde seu surgimento em meados do século XX, tomou proporções mundiais e seu impacto na economia e na sociedade aumenta a cada ano, seja de forma direta por meio da realização de projetos nas mais distintas áreas de graduação ou indireta por meio da inserção de profissionais capacitados, dinâmicos e inovadores no mercado de trabalho. Dentre os diferentes setores do mercado, a Engenharia foi fortemente impactada por esse movimento, pois o mesmo trouxe uma mudança de mentalidade para os futuros profissionais da área e o que se espera deles. O presente artigo tem por objetivo retratar a importância do MEJ na formação profissional do engenheiro do futuro, colocando em perspectiva o seu viés acadêmico e extracurricular do ponto de vista dos estudantes que fazem ou já fizeram parte do movimento. Para tal, foi realizado um formulário para confirmar a proporção de aprendizado e desenvolvimento de competências proporcionado pelas empresas juniores (EJs) de todo o Brasil. Além disso, enfatizou-se a influência e contribuição do movimento na Universidade Federal Fluminense. A partir da metodologia utilizada, foram obtidas respostas de uma parcela representativa do MEJ que comprovaram a influência positiva do mesmo no desenvolvimento de diversas soft skills, o qual culmina na formação de um profissional mais preparado tanto no viés acadêmico quanto empresarial, se destacando no competitivo mercado da engenharia.
\end{abstract}

Palavras-chaves: Empresa Júnior. Mercado de trabalho. Engenharia. Soft skills. Hard skills.

\section{INTRODUÇÃO}

As inovações tecnológicas contemporâneas têm mudado a forma como as pessoas se relacionam umas com as outras, demandando que os profissionais se adaptem a essa nova realidade. Hoje, as habilidades técnicas adquiridas durante a graduação precisam ser cada vez mais aperfeiçoadas enquanto, simultaneamente, é necessário desenvolver competências relacionadas ao comportamento e postura do profissional no mercado de trabalho.

A Indústria 4.0 marca um momento no qual as máquinas são utilizadas como suporte para soluções personalizadas, eficientes e criativas, criando condições de possibilidades para que o profissional seja mais produtivo, ao automatizar tarefas burocráticas e operacionais, permitindo que este foque seus esforços em atividades que gerem um maior impacto e resultado 
dentro do ecossistema corporativo (CUNHA e SOUZA, 2015). Tal avanço promove um mercado mais competitivo, eficiente, tecnológico e inovativo. A engenharia ganha um papel de destaque por ser pioneira nesse processo evolutivo, surgindo assim o conceito do engenheiro do futuro, do qual se espera um domínio das novas tecnologias, formação multidisciplinar e competências emocionais como características essenciais.

Neste cenário, surge a necessidade de desenvolver alternativas que possibilitem ao estudante de engenharia uma formação que contemple habilidades ligadas às hard e soft skills. As soft skills dizem respeito às habilidades geradas pela personalidade do indivíduo, isto é, consistem em competências mentais, comportamentais e sociais (criatividade, inovação, liderança, dinamismo). Já as hard skills remetem aos tipos de conhecimentos específicos que são aprendidos academicamente e facilmente quantificados (gestão de projetos, inglês, Microsoft office, gestão de pessoas). (CUNHA e SOUZA, 2015)

Assim, o Movimento Empresa Júnior (MEJ) entra como agente promotor na otimização de conhecimento, proporcionando ao estudante o desenvolvimento de habilidades comportamentais, além de unir os saberes teóricos e práticos, por intermédio de uma vivência empresarial durante a graduação. Este está alinhado ao processo de globalização que exige do engenheiro foco em resultado, desenvolvimento de metas, análises de dados e agilidade.

O objetivo deste artigo é discutir o papel que as Empresas Juniores (EJs) representam na formação do engenheiro a partir da perspectiva dos próprios estudantes, enfatizando o amplo impacto e a capacidade do movimento de ser um agente potencializador de conhecimento e desenvolvimento de habilidades Tal análise sobre o impacto das EJs de engenharia na concepção do profissional será feita com base nos aprendizados e vivências compartilhados por intermédio de um formulário respondido por estudantes de engenharia participantes do movimento em todo o Brasil. O trabalho também discutirá a influência do MEJ em diversos cursos de engenharia da UFF.

\section{REFERENCIAL TEÓRICO}

O MEJ surgiu em 1967 em Paris, na França, devido à percepção dos alunos de ensino superior sobre a necessidade de complementar sua formação e se aproximar do mercado de trabalho. Desde essa época, vem se expandindo pelo globo e enriquecendo a formação de estudantes nas mais diversas áreas, dentre elas a Engenharia. O Movimento chegou ao Brasil em 1987, com o surgimento inicial de EJs em universidades do Sudeste, estando hoje presente em todos os estados do país, nos quais foram implementadas as suas respectivas Federações.

Fundada apenas no início do século XXI, a Confederação Brasil Júnior é a instituição que buscou regulamentar o movimento frente à sociedade, organizando suas metas e propósitos com os Planejamentos Estratégicos da rede e conectando todos os empresários juniores do país sob a missão de "formar, por meio da vivência empresarial, empreendedores comprometidos e capazes de transformar o Brasil”. O movimento adquiriu sua legitimação perante aos órgãos públicos a partir da publicação da Lei 13.267, de 6 de abril de 2016. (BRASIL, 2016)

Dentre os valores da Brasil Júnior, encontram-se postura empreendedora, foco em resultado, sinergia e transparência, os quais contemplam características fundamentais buscadas atualmente no mercado de trabalho. Essas características mostram como as soft skills tem ganhado importância frente ao contexto da Era Digital e Indústria 4.0 que estamos vivenciando. Anualmente é feito pelo LinkedIn um levantamento das habilidades que serão mais valorizadas no mercado, sejam elas técnicas ou emocionais. A edição de 2020 do Workplace Learning Report mostrou um crescimento na valorização das soft skills. Neste documento, a coordenadora 
de Atração e Seleção da Unimed, Cristina Ferreira, afirma "habilidades técnicas são importantes, mas se não existir a atitude, só conhecimento, nada acontece. Para se adaptar ao mercado de trabalho no mundo VUCA - volátil, incerto, complexo e ambíguo - mais do que nunca, é preciso ter as competências comportamentais, como equilíbrio e adequação ao meio com que interagem". (WHOW!, 2020)

As Diretrizes Curriculares Nacionais do Curso de Graduação em Engenharia, explicitadas pela Resolução $\mathrm{n}^{\circ} 2$, de 24 de abril de 2019, destacam, em seu Art $3^{\circ}$, item I que, dentre as competências esperadas do egresso nos cursos de engenharia, é preciso "ter visão holística e humanista, ser crítico, reflexivo, criativo, cooperativo e ético e com forte formação técnica". Tal diretriz está em sintonia com as expectativas do novo mercado de trabalho, quanto a capacidade tanto técnica quanto humana dos engenheiros do futuro.

É possível traçar um paralelo entre o propósito do MEJ com a aquisição tanto de hard skills quanto de soft skills por parte dos profissionais da engenharia. Temos que "desde 2010, o MEJ já impactou mais de $\mathrm{R} \$ 70.000 .000,00$ na economia brasileira, que são integralmente reinvestidos na educação empreendedora dos estudantes" (BRASIL JÚNIOR, 2020). O próprio movimento busca ser "sustentável", usando de seus recursos para desenvolver habilidades e competências em seus membros de forma que eles retornem tal investimento para o mercado, seja no âmbito júnior ou sênior.

\section{A CONTRIBUIÇÃO DO MEJ NA CONCEPÇÃO DO ENGENHEIRO}

A Indústria 4.0 exige profissionais versáteis, dinâmicos, ágeis e que resolvam problemas complexos. Nesse sentido, a Universidade vem construindo mecanismos que proporcionem ao estudante uma formação que não seja limitada à parte técnica e teórica, buscando o desenvolvimento advindo de experiências práticas que estimulem a aquisição de hard e soft skills. "As competências se enriquecem também com todas as aptidões que se destacam dos saberes técnicos: saber-ser, saberes-sociais, capacidade de se comunicar, representações" (ROPÉ; TANGUY, 2004, p.141).

Uma das maneiras de se conseguir moldar o engenheiro do futuro consiste em apresentar ao aluno experiências prática e contato com a realidade que conduzam ao questionamento, os quais são possibilitados pela EJ. Além disso, observa-se que as EJs estão inseridas num contexto de formação em engenharia que se conectam os pilares do tripé-universitário, ou seja, pesquisa, ensino e extensão. A pesquisa, por exemplo, quando se realiza a segmentação de mercado para atender um público alvo, levantamento de metodologias para desenvolver o escopo de um novo projeto, e serviços de consultoria da área de P\&D (Pesquisa \& Desenvolvimento). A extensão pode ser evidenciada através dos serviços sem fins lucrativos, desde pequenos e médios empresários a grandes multinacionais, visando o aprendizado dos alunos e no fomento ao desenvolvimento econômico e social nacional. E, por fim, o ensino, pois as atividades realizadas pelos membros são acompanhadas e orientadas por professores.

Assim, as EJs de engenharia proporcionam uma complementação da formação para o mercado. $\mathrm{O}$ estudante que está inserido nesse meio estimula a habilidade de trabalhar em grupo, relacionamento interpessoal, visão de negócios, capacidade administrativa, inteligência emocional e estratégica e planejamento de projetos. Com esse aprendizado, fica muito mais fácil ser um engenheiro capaz de impactar e transformar o ecossistema em que atua.

O engenheiro 4.0 assume um papel cada vez mais estratégico e relevante nas organizações, que passaram a requerer competências emocionais alinhadas ao conhecimento teórico como respostas para as novas exigências e desafios do mercado. Tais competências 
podem ser adquiridas a partir da vivência empresarial promovida pelo MEJ. Essas são as inerentes à própria pessoa, tem potencial para serem desenvolvidas e aprimoradas e, além disso, podem ser divididas em (CATHO, 2019):

- Intelectuais: necessárias para reconhecer e definir problemas, equacionar soluções, pensar estrategicamente, introduzir modificações no processo de trabalho, atuar preventivamente, transferir e generalizar conhecimentos;

- Comunicativas: utilizadas na forma de expressão e comunicação com seu grupo, superiores hierárquicos ou subordinados, clientes internos e externos, facilitando o trabalho em equipe, o diálogo, e o exercício da negociação;

- Sociais: são atitudes e comportamentos necessários para que conhecimentos da vida cotidiana sejam transferidos para o ambiente de trabalho e vice-versa;

- Comportamentais: necessárias para demonstrar espírito empreendedor e capacidade para a inovação, como por exemplo, iniciativa, criatividade, vontade de aprender, abertura às mudanças, consciência da qualidade e das implicações éticas do seu trabalho;

- Organizacionais: necessárias para compreensão do negócio, seus objetivos, relações com o mercado, ambiente sócio político, planejamento do escopo de projetos e orientação para o cliente.

Ao fazer parte de uma EJ, o estudante de engenharia tem a oportunidade de gerenciar projetos, conquistando uma maturidade profissional, além de experiência em gerenciamento de tempo, recursos e gestão de pessoas. Além disso, é um momento no qual ocorre o desenvolvimento e crescimento ao máximo em relação às suas capacidades de comunicação e negociação, pois há muito contato com clientes, parceiros, patrocinadores, professores e outros stakeholders. Outro ponto importante é o fomento do networking entre profissionais, empresas, professores universitários, além de toda uma rede de juniores e pós-juniores.

Portanto, fica evidente que o MEJ tem como objetivo agregar o máximo de competências (hard e soft skills), fazendo então parte das esferas que constituem o profissional, em conjunto com a Universidade e o professor.

\section{A PRESENÇA DO MEJ NA UNIVERSIDADE FEDERAL FLUMINENSE}

\subsection{MEJ e a representatividade na UFF}

O MEJ está oficialmente presente em todos os estados brasileiros, sendo representado por suas respectivas federações e já se instaurou em mais de 200 Instituições de Ensino Superior (IES). A UFF teve contato com o movimento há quase duas décadas, com a criação da EJ Meta Consultoria em 1995, e serviu como um polo tecnológico extremamente propício para a sua repercussão e desenvolvimento nos cursos superiores em diferentes polos da Universidade (Niterói, Rio das Ostras, Volta Redonda).

Hoje, a RioJunior - Federação de Empresas Juniores do Estado do Rio de Janeiro - possui 57 EJs já federadas. Outras empresas juniores estão se estruturando para entrar na Federação, fato que mostra como este é um mercado em potencial crescimento. A UFF possui 15 EJs federadas, $26 \%$ do total, sendo sete de engenharia. Isto mostra que os cursos de engenharia são tanto pioneiros em trazer o movimento para a universidade quanto ainda possuem presença marcante no âmbito Junior da instituição.

Esses dados mostram como os futuros engenheiros graduados na UFF têm oportunidade de se beneficiar de uma educação mais panorâmica, complementando seus estudos acadêmicos com uma visão real e preparativa de mercado. As empresas de engenharia associadas à UFF 
são: Agrha (2011), Focus Consultoria (2009), Meta Consultoria (1995), P\&Q Engenharia Jr. (2010), Pulso (2005), SmartTel Jr. (2015) e Tesla Jr. (2015). Estas empresas contemplam as mais diversas engenharias, o que proporciona também a difusão de conhecimento dentre estes cursos, gerando materiais, capacitações e até mesmo projetos em parceria, o que aumenta as possibilidades de inserção e equiparação ao mercado sênior.

\subsection{Apresentação Institucional: P\&Q Engenharia Jr.}

A empresa que proporcionou a vivência empresarial e desenvolvimento profissional por meio do MEJ para ambos os autores do presente artigo foi a P\&Q Engenharia Jr., situada na UFF, a qual contempla alunos dos cursos de Engenharia de Petróleo, Engenharia Química e Química Industrial. A P\&Q completa este ano uma década de muita história.

Fundada em 2010, a EJ construiu seu reconhecimento na universidade e se estabeleceu num espaço próprio dentro da mesma nos seus primeiros 2 anos. Em 2014, a empresa realiza o Engrena, nome dado a seu processo seletivo, e começa a efetivamente realizar projetos para o mercado. Nesse momento, a empresa passa a estruturar sua gestão de recursos, tanto pessoas quanto finanças e ao longo do ano se molda aos padrões de gerenciamento da RioJunior, conquistando sua federação em 2015.

Os últimos cinco anos de resultados apresentaram crescimento exponencial, como é possível verificar no gráfico abaixo. A P\&Q passou a ter um portfólio mais definido, o qual vem sendo aprimorado até hoje, e o escopo de seus projetos começam a incluir soluções de engenharia cada vez mais complexas, refletindo em seus números.

Gráfico 1: Resultados P\&Q Engenharia Jr. nos últimos 5 anos

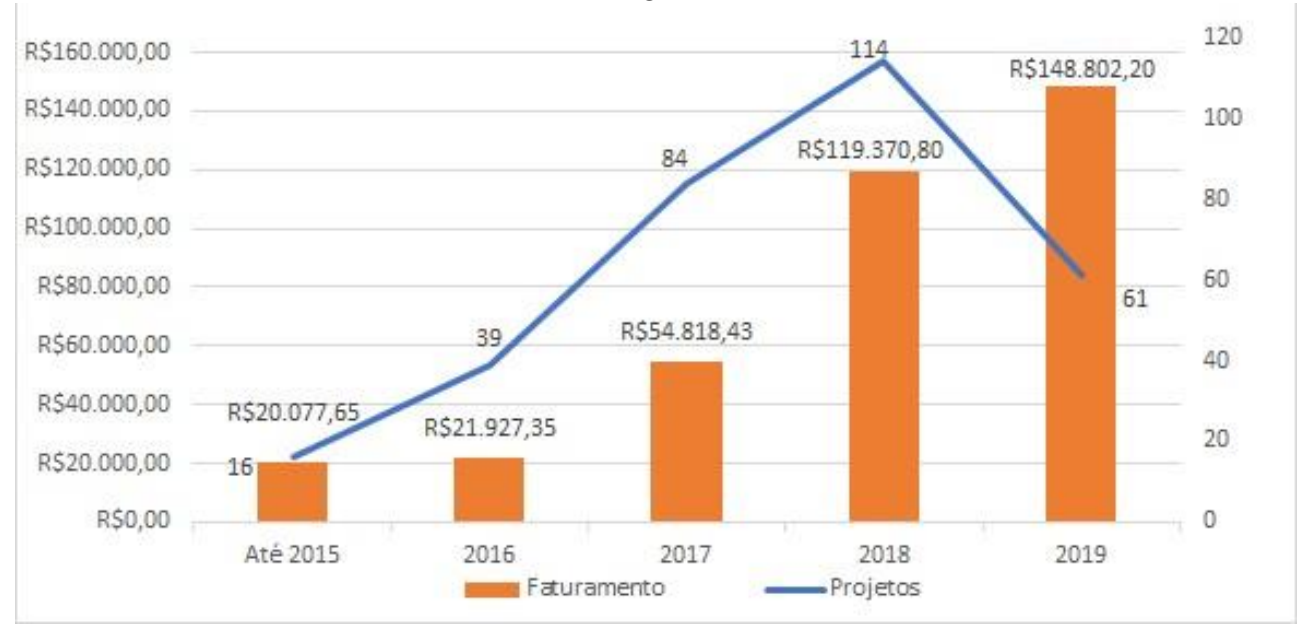

Fonte: Elaboração Própria a partir de dados da Brasil Júnior

A P\&Q além de ter superado suas próprias metas ao longo dos anos, ganhou lugar de destaque entre as EJs do Rio de Janeiro em termos de faturamento no ano passado e vem mantendo essa posição ao longo do ano de 2020, como é possível observar nas tabelas abaixo. 
Quadro 1: Ranking Rio Junior 2018

\begin{tabular}{|l|c|c|}
\hline \multicolumn{1}{|c|}{ Empresa Junior } & Projetos & Faturamento \\
\hline Fluxo Consultoria & 317 & $\mathrm{R} \$ 1.013 .652,11$ \\
\hline AlQualis Jr. & 4 & $\mathrm{R} \$ 238.874,00$ \\
\hline Empresa Júnior Meta & 68 & $\mathrm{R} \$ 152.737,60$ \\
\hline Ayra Consultoria & 67 & $\mathrm{R} \$ 150.603,62$ \\
\hline CEFET Jr. & 54 & $\mathrm{R} \$ 137.671,81$ \\
\hline Pulso Consultoria & 61 & $\mathrm{R} \$ 126.547,31$ \\
\hline P\&Q Engenharia Jr & 114 & $\mathrm{R} \$ 119.370,80$ \\
\hline Hidros Consultoria & 56 & $\mathrm{R} \$ 101.176,25$ \\
\hline Ibmec Jr. & 38 & $\mathrm{R} \$ 93.943,87$ \\
\hline
\end{tabular}

Fonte: Elaboração Própria a partir de dados da Brasil Júnior

Quadro 2: Ranking Rio Junior 2019

\begin{tabular}{|l|c|c|}
\hline \multicolumn{1}{|c|}{ Empresa Junior } & Projetos & Faturamento \\
\hline Fluxo Consultoria & 569 & $\mathrm{R} \$ 1.362 .805,50$ \\
\hline Pulso Consultoria & 67 & $\mathrm{R} \$ 188.048,60$ \\
\hline Empresa Júnior Meta & 93 & $\mathrm{R} \$ 186.501,02$ \\
\hline Hidros Consultoria & 71 & $\mathrm{R} \$ 172.426,70$ \\
\hline Ibmec Jr. & 47 & $\mathrm{R} \$ 157.425,32$ \\
\hline P\&Q Engenharia Jr. & 61 & $\mathrm{R} \$ 148.802,20$ \\
\hline Ayra Consultoria & 83 & $\mathrm{R} \$ 142.679,04$ \\
\hline CEFET Jr. & 58 & $\mathrm{R} \$ 122.895,75$ \\
\hline IME Jr. & 48 & $\mathrm{R} \$ 120.494,00$ \\
\hline
\end{tabular}

Além de ter seu potencial expresso pelos números, a $\mathrm{P} \& \mathrm{Q}$ forma não apenas profissionais capacitados tecnicamente, como pessoas de visão holística, empatia e ética que futuramente irão compor o mercado de trabalho. Os valores da EJ refletem de forma personalizada algumas das soft skills buscadas pelos empregadores atualmente: proatividade, liderança, foco, excelência e empatia. Dessa forma, a empresa consegue preparar o graduando para se tornar o que é esperado de um engenheiro do futuro, com as devidas competências técnicas e emocionais.

\subsection{Metodologia}

Tendo por objetivo quantificar como o MEJ influenciou a formação profissional de estudantes das diversas engenharias foi realizado uma pesquisa quantitativa e qualitativa. A primeira etapa consistiu na identificação do público alvo da pesquisa: estudantes de graduação em engenharia das Universidades brasileiras que foram membros do movimento durante sua formação. Na segunda etapa, foi estruturado um formulário composto de oito perguntas, pautado na experiência e no aprendizado de competências durante o período que os discentes fizeram parte da EJ. A terceira etapa consistiu, na divulgação do formulário por grupos ligados ao MEJ nas seguintes plataformas: Whatsapp, Facebook e Linkedln. Na quarta e última etapa foi realizada a análise dos dados, que contaram com 144 respostas.

\section{RESULTADOS E DISCUSSÕES}

I) Qual o seu curso de graduação?

Essas perguntas refletem o perfil do nosso público alvo, o qual compreende uma grande quantidade de áreas na engenharia, mostrando como o mercado tem se diversificado e cada vez mais soluções estão sendo oferecidas a sociedade por estudantes dessas graduações. 
Gráfico 2: resultados obtidos para questão 1 do formulário usado como metodologia

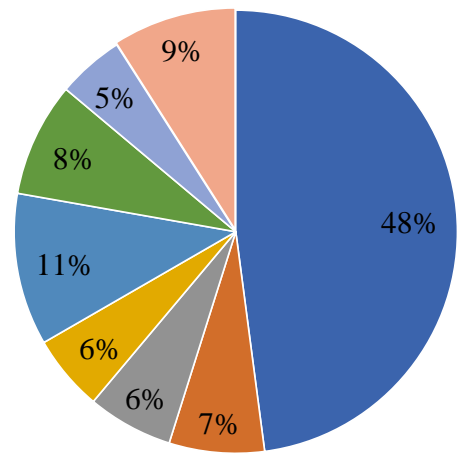

- Engenharia Química

- Engenharia Elétrica

- Engenharia de Petróleo

- Engenharia Civil

- Engenharia de Produção

- Engenharia Ambiental

- Engenharia de Telecomunicações

- Outros

Fonte: Elaboração própria

II) Por quanto tempo você foi membro de EJ?

$\mathbf{2 2 , 2 \%}$ ficaram por um período de $\mathbf{+ 1 8}$ meses

29,9\% ficaram por um período entre 12 e 18 meses

7,7\% ficaram por um período entre 6 e 12 meses

$\mathbf{6 , 9 \%}$ ficaram por um período de $\mathbf{6}$ meses

Conclui-se que nossos juniores alvo já adquiriram certa experiência e puderam sentir o impacto do MEJ em sua trajetória pessoal e profissional.

III) O quanto a sua EJ te ajudou a se familiarizar com o seu curso de graduação?

$\mathbf{7 8 , 5} \%$ classificaram como 4 e 5

$13,9 \%$ classificaram como 3

$\mathbf{7 , 7 \%}$ classificaram como 1 e 2

Os cursos de engenharia têm como um dos seus principais problemas a evasão de alunos, causado principalmente pelas matérias complexas no início da graduação ou pela demora para os graduandos terem contado com matérias específicas de cada curso. Tendo em vista essa realidade, observa-se que o MEJ contribui de forma significativa para que o estudante conheça seu mercado de atuação, motivando-o e trazendo familiaridade com a profissão escolhida.

IV) $O$ quanto a sua EJ contribui para que você adquirisse habilidades/competências além do esperado no seu curso de graduação? $89,6 \%$ classificaram como 4 e 5

$\mathbf{9 \%}$ classificaram como 3

$1,4 \%$ classificaram como 1 e 2

As diretrizes gerais dos cursos de engenharia ressaltam que as habilidades/competências devem ser trabalhadas em consonância com as disciplinas técnicas. Porém, o que se nota na realidade são grades curriculares com a ausência de disciplinas que desenvolvam competências essenciais para o engenheiro 4.0, como gerenciamento de pessoas, gestão de riscos, negociação e planejamento de projetos, dentre outras. O MEJ entra nesse cenário com o papel de suprir essa deficiência, proporcionando que o estudante adquira tais habilidades durante a sua passagem pelo movimento. 
V) Depois da sua participação no MEJ, você se sentiu inclinado a empreender?

$\mathbf{5 1 , 4 \%}$ dos estudantes responderam Sim

$\mathbf{4 3 , 3 \%}$ dos estudantes responderam Talvez

3\% dos estudantes responderam Não

A partir dos dados coletados, vemos que pouco mais de $90 \%$ dos juniores respondentes foram influenciados a empreender ao longo de sua carreira devido às visões de negócio e experiência profissional adquiridas no MEJ. É válido ressaltar que o movimento nos mostra como ser empreendedor não se resume a ter um negócio próprio. Os jovens podem ser empreendedores dentro de suas respectivas posições em grandes empresas, apresentando ideias inovadoras, críticas bem fundamentadas e tendo capacidade de liderança. Ter esse espírito independentemente de se tornar autônomo ou não constrói um profissional melhor e mais preparado para a Indústria 4.0.

VI) O quanto você acredita que a EJ pode contribuir para sua entrada no mercado de trabalho (estágio/emprego)?

$\mathbf{9 5 , 8} \%$ classificaram como 4 e 5

3,5 \% classificaram como 3

$0,7 \%$ classificaram como 1 e 2

Essa pergunta retrata um dos focos principais do artigo, evidenciando quantitativamente o quanto a participação no movimento influencia a entrada dos graduandos no mercado de trabalho. Dentre as opções conferidas (mesmas que a 3 e 4), vemos que aproximadamente 95\% dos estudantes de engenharia que se disponibilizaram a responder a pesquisa puderam sentir um reflexo em sua entrada no mercado sênior e trajetória profissional causado pelos benefícios de ter sido um membro do movimento. O MEJ prepara os graduandos para o mercado de trabalho, pois os aproxima do mesmo desde cedo na graduação, fazendo com que os mesmos se acostumem com o ambiente corporativo, desde a estrutura de processos seletivos até como se portar, em adição ao aprendizado técnico adquirido na EJ.

VII) Quais competências você acredita ter desenvolvido fazendo parte do MEJ?

A partir das respostas, as competências mais escolhidas foram: trabalho em equipe, proatividade e resolução de problemas. $\mathrm{O}$ trabalho em equipe é importante devido à alta multidisciplinaridade de profissionais que atuam nos projetos engenharia, ou seja, diferentes profissionais buscando soluções inovadoras. A proatividade por sua vez está ligada a iniciativa, assumir responsabilidades, foco em resultado e na busca de estar antecipando problemas, com soluções ordenadas e claras. Já, a resolução de problemas surge inerente às novas barreiras que a engenharia está desbravando com projetos complexos e audaciosos, pautados na responsabilidade socioambiental, necessitando assim de profissionais preparados para buscar respostas eficientes e seguras. Portanto, fica evidente que a experiência no MEJ, propicia ao aluno uma experiência única, que forma um profissional mais preparado para enfrentar os desafios da indústria 4.0. 
Quadro 3: Competências desenvolvidas pelo MEJ

\begin{tabular}{|l|c|c|c|c|c|}
\hline \multicolumn{1}{|c|}{ Competências } & $\begin{array}{c}\text { Extremamente } \\
\text { Desenvolvido }\end{array}$ & $\begin{array}{c}\text { Muito } \\
\text { Desenvolvido }\end{array}$ & Desenvolvido & $\begin{array}{c}\text { Pouco } \\
\text { Desenvolvido }\end{array}$ & $\begin{array}{c}\text { Não } \\
\text { Desenvolvido }\end{array}$ \\
\hline Trabalho em equipe & $59 \%$ & $31 \%$ & $10 \%$ & $1 \%$ & $0 \%$ \\
\hline Proatividade & $53 \%$ & $31 \%$ & $15 \%$ & $2 \%$ & $0 \%$ \\
\hline Resolução de Problemas & $48 \%$ & $40 \%$ & $13 \%$ & $0 \%$ & $0 \%$ \\
\hline Oratória/Comunicação & $42 \%$ & $34 \%$ & $24 \%$ & $1 \%$ & $0 \%$ \\
\hline Liderança & $38 \%$ & $40 \%$ & $22 \%$ & $1 \%$ & $0 \%$ \\
\hline Inovação/Criatividade & $36 \%$ & $31 \%$ & $28 \%$ & $3 \%$ & $1 \%$ \\
\hline Inteligência emocional & $28 \%$ & $33 \%$ & $29 \%$ & $8 \%$ & $1 \%$ \\
\hline Metodologias Ágeis & $24 \%$ & $38 \%$ & $22 \%$ & $13 \%$ & $3 \%$ \\
\hline Gestão de Tempo & $24 \%$ & $35 \%$ & $33 \%$ & $8 \%$ & $0 \%$ \\
\hline Microsoft Office & $19 \%$ & $22 \%$ & $49 \%$ & $8 \%$ & $3 \%$ \\
\hline
\end{tabular}

Fonte: Elaboração Própria

VIII) Você como júnior/pós júnior tem algum depoimento a dar?

$\mathrm{Na}$ última questão, buscamos coletar alguns depoimentos dos juniores e pós juniores dispostos a contar como o MEJ influenciou na formação acadêmica e carreira deles, dentre os quais um chamou muita atenção, pois reflete precisamente o que buscamos mostrar a comunidade acadêmica com o presente artigo:

"A vivência do MEJ foi imprescindivel para saber como funciona o mercado de trabalho, desde o processo seletivo até a área de atuação, desenvolvendo competências individuais e coletivas de cada membro. O universitário que participa de alguma Empresa Júnior antes de iniciar sua carreira profissional, já está mais apto e preparado para ingressar no mercado de trabalho."

\section{CONSIDERAÇÕES FINAIS}

Os ensinos superiores dos cursos de engenharia no Brasil incluem uma enorme gama de conhecimento técnico a ser transmitido aos futuros profissionais, porém compreendido na grade obrigatória dos cursos não vemos disciplinas capazes de desenvolver as competências emocionais desses engenheiros do futuro. Tais habilidades - soft skills - podem ser adquiridas participando de diversas atividades extracurriculares ao longo da formação, dentre elas as EJs.

As EJs são, como foi refletido nos resultados, um dos maiores polos de aquisição de conhecimento alinhado a vivência empresarial ao qual temos acesso dentro das IES. Muitos ex membros destas instituições mostraram como as mesmas contribuíram para sua entrada no mercado de trabalho ou seu interesse por uma abordagem empreendedora, mostrando também como as empresas juniores estão acompanhando os pilares do mundo VUCA e se adequando ao novo conceito de engenheiro do futuro demandado pela Indústria 4.0 crescente no mundo.

Este artigo toma como base o princípio de que o engenheiro de hoje já diferente do que era esperado no século XX ou até mesmo início do XXI, portanto espera-se que, com a Era Digital resultante da última revolução industrial, sejam exigidas mais habilidades e competências por parte do engenheiro do amanhã. Este precisará se inserir em um mercado mais inovador, criativo, versátil e seletivo e com pessoas cada vez mais preparadas. A rede formada pelo MEJ tem exercido um grande papel nessa adaptação dos atuais graduandos em profissionais capazes e resilientes, verdadeiros engenheiros do futuro. 


\title{
7. REFERÊNCIAS BIBLIOGRÁFICAS
}

BLOG WHOW! As soft skills mais valorizadas no mercado de trabalho. Disponível em: whow.com.br/comportamento/soft-skills-valorizadas-trabalho/. Acesso em: 23 de junho de 2020.

BRASIL JÚNIOR, 2020. Disponível em: https://www.brasiljunior.org.br/. Acesso em: 13 de julho de 2020.

BRASIL. Lei n. 13.267, de 06 de abril de 2016. Disciplina a criação e a organização das associações denominadas empresas juniores, com funcionamento perante instituições de ensino superior. Brasília,DF, 2016.

CATHO EMPRESAS. Modelos de Habilidades e Competências. Disponível em: https://www.catho.com.br/salario/action/artigos/Modelos_de_Habilidades_e_Competencias.p hp. Acesso em: 13 de junho de 2020.

CUNHA, A. A.; SOUZA, V. C. A. Contribuições da Empresa Júnior para a formação profissional dos estudantes de química e engenharia química da UFV. 2015. 15 f. Curso de Engenharia de Química, Departamento de Engenharia Química, Universidade Federal de Viçosa, Viçosa, 2015.

MINISTÉRIO DE EDUCAÇÃO E CULTURA (MEC). Resolução CNE/CES 04/2019. Institui as Diretrizes Curriculares Nacionais do Curso de Graduação em Engenharia. Diário Oficial da União, Brasília, 23 de abril de 2019.

ROPÉ, Françoise; TANGUY, Lucie (Orgs.). Saberes e competências: o uso de tais noções na escola e na empresa. 5. ed. Campinas: Papirus, 2004. 207p.

\section{THE IMPACT OF THE JUNIOR COMPANY MOVEMENT IN THE FUTURE ENGINEERS GRADUATION}

\begin{abstract}
The Junior Enterprise Movement (JEM), since its beginning in the mid-twentieth century, has taken on global proportions and its impact on the economy and society increases every year, either directly through the development of projects in the most distinct areas of graduation or indirectly through the entry of trained, dynamic and innovative professionals in the labor market. Among the different market sectors, Engineering was severely impacted by this Movement, as it brought a mindset change to the future professionals of the area and what is expected of them. This article aims to reproduce the importance of the JEM in the engineers of the future professional training, putting in perspective their academic and extracurricular bias from the point of view of college students who are or have already been part of the movement. To this end, a Google form was elaborated to confirm and measure the learning and skills development provided by junior companies (JCs) from all over Brazil. In addition, it was emphasized about the influence and contribution of the movement at the Fluminense Federal University. From the methodology applied in the study, we obtained answers from a representative portion of the JEM that reassured its positive contribution for the development of several soft skills, which culminates in the formation of a professional better prepared in both academic and business bias, standing out in the competitive engineering market.
\end{abstract}

Keywords: Junior Enterprise. Labor market. Engineering. Soft skills. Hard skills. 